\title{
A METHOD TO ANALYZE THE MACHINING ACCURACY RELIABILITY SENSITIVITY OF MACHINE TOOLS BASED ON FAST MARKOV CHAIN SIMULATION
}

\author{
PODEJŚCIE DO ANALIZY CZUŁOŚCI NIEZAWODNOŚCIOWEJ \\ DOKŁADNOŚCI OBRABIAREK OPARTE NA SYMULACJI METODA \\ SZYBKICH ŁAŃCUCHÓW MARKOWA
}

\begin{abstract}
With the ever increasing demand of higher machining accuracies, the machining accuracy reliability has evolved into an indicator to evaluate the performance of a machine tool. Consequentially, methods for improving the machining accuracy reliability have become the focus of attention for both manufacturers and users. Generally, the intercoupling geometric errors are the main cause which may lead to a reduction of the machining accuracy of machine tools. In this paper, the machining accuracy reliability is defined as the ability of a machine tool to perform at its specified machining accuracy under the stated conditions for a given period of time, and a new approach for analyzing the machining accuracy reliability of machine tools based on fast Markov chain simulations is proposed. Using this method, seven different failure modes could be determined for a machine tool. An analysis of the machining accuracy reliability sensitivity was performed based on solving the integral of the failure probability of the machine tool, and the key geometric errors which most strongly affect the machining accuracy reliability were identified. Finally, in this study, a 4-axis machine tool was selected as an example to experimentally validate the effectiveness of the proposed method.
\end{abstract}

Keywords: machining accuracy reliability, machine tool, Fast Markov Chain, reliability sensitivity analysis, integral of failure probability.

\begin{abstract}
Wraz z wciąz rosnacym zapotrzebowaniem na coraz to wyższa dokładność obróbki, niezawodność dokładności obróbki stała się wskaźnikiem pozwalającym na ocenę charakterystyk obrabiarek. W rezultacie, metody doskonalenia niezawodności doktadności obróbki znalazły się w centrum uwagi zarówno producentów jak i użytkowników tych maszyn. Na ogót, do zmniejszenia dokładności obróbki prowadza nakładajace się błędy geometryczne. W niniejszej pracy, niezawodność dokładności obróbki zdefiniowano jako zdolność obrabiarki do pracy z określona dla niej doktadnościa w zadanych warunkach przez dany okres czasu. Zaproponowano nowe podejście do analizy niezawodności dokładności obróbki oparte na symulacji metoda szybkich łańcuchów Markowa. Za pomoca tej metody, można ustalić siedem różnych przyczyn uszkodzeń obrabiarki. Analizę czułości niezawodnościowej dokładności obróbki przeprowadzono obliczając całkę prawdopodobieństwa uszkodzenia obrabiarki. Określono także kluczowe błędy geometryczne, które najsilniej wpływaja na niezawodność doktadności obróbki. Wreszcie, efektywność proponowanej metody sprawdzono doświadczalnie na przykładzie obrabiarki czteroosiowej.
\end{abstract}

Stowa kluczowe: niezawodność dokładności obróbki, obrabiarka, szybki łańcuch Markowa, analiza czułości niezawodnościowej, catka prawdopodobieństwa uszkodzenia.

\section{Introduction}

Multi-axis CNC machine tools are typical mechatronic devices with high added value and a wide range of applications. Achieving a high machining accuracy is adamant to ensure a high quality and performance of the machined mechanical product and the machining accuracy is therefore an important consideration for any manufacturer [30]. Machining accuracy is influenced by machining errors belonging to several categories, e.g. kinematics errors, thermal errors, cutting force induced errors, servo errors and tool wear [3]. It is influenced by a variety of machining errors which can be divided into several categories, e.g., kinematics errors, thermal errors, errors induced by the cutting force, servo errors and tool wear [3]. Among these different error sources, the geometric error of the machine tool components and structures is one of the biggest sources of inaccuracy, accounting for about $40 \%$ of all errors. Therefore, methods for improving the machining accuracy of $\mathrm{CNC}$ machine tools have become a hot topic recently.

\subsection{Volumetric error model}

In order to improve the machining accuracy of $\mathrm{CNC}$ machine tools, the theoretical modeling of errors is crucial to maximize the performance of these machine tools [4]. Error modeling can provide a systematic and suitable way to establish the error model for a given $\mathrm{CNC}$ machine tool. In recent years, many studies have focused on modeling multi-axis machine tools to determine the resultant error of individual components in relation to the set-point deviation of the tool and the workpiece. Furthermore, the various methods for modeling the geometric errors from different perspectives have experienced a gradual development [7]. To describe the error of the cutter location and the tool orientation between the two kinematic chains, the error model is normally established using homogeneous transformation 
matrices (HTM) [10, 18, 20], denavit-hartenberg (D-H) method [16], modified denavit-hartenberg (MD-H) method [19], or multi-body system (MBS) theory [31, 32]. Among these different approaches, MBS theory, first proposed by Houston, has evolved into the best method for the modeling of geometric errors of machine tools because it provides for a simple and convenient method to describe the topological structure of an MBS [21].

\subsection{Reliability analysis}

After the error model for a given machine tool has been established, the next step is to study the machine tool's machining accuracy reliability. Recently, several studies have been published which reported on the reliability of mechanical systems from different perspectives. For instance, Du et al. has summarized three useful ways to improve the reliability of a machine, including (1) changing the mean values of random variables, (2) changing the variances of random variables, and (3) a truncation of the distributions of random variables [9]. Tang proposed a new method based on graph theory and Boolean functions for assessing the reliability of mechanical systems [26]. Avontuur and van der Werff proposed a new method for analyzing the reliability of mechanical and hydraulic systems based on finite element equations, which describe the motion of and the equilibrium between internal and external loads for structures and mechanisms [1]. Lin investigated the reliability and failure of face-milling tools when cutting stainless steel and the effect of different cutting conditions (cutting speed, feed, cutting depth) on the tool life [22]. Chen et al. performed a reliability estimation for cutting tools based on a logistic regression model using vibration signals [5]. However, to the best of our knowledge, there have been no studies on the machining accuracy reliability of $\mathrm{CNC}$ machine tools. The machining accuracy reliability refers to the tool's ability to perform at its specified machining accuracy. In general, the volumetric error of a machine tool can be divided into the errors corresponding to the X-, Y-, and Z-directions, respectively. The machining errors in each direction are likely to exceed the required machining accuracy, thereby effectively rendering the machine inaccurate and unreliable, and thus unusable. Consequentially, the machining accuracy of a machine tool is related to many different failure modes.

\subsection{Sensitivity analysis}

However, many different geometric errors have to be taken into account when modeling a multi-axis machine tool. For example, there are 29 geometric errors for a 4-axis machine tool. These geometric errors are interacting, and how to determine their degree of influence on the machining accuracy reliability is currently a difficult problem of machine tool design $[14,40]$. Performing a sensitivity analysis is one possibility to identify and quantify the relationships between input and output uncertainties [29]. A variety of sensitivity analysis methods have been published in literature. For instance, Ghosh et al. proposed a new approach for a stochastic sensitivity analysis based on first-order perturbation theory [12]. Chen et al. established a volumetric error model and performed a sensitivity analysis for a 5-axis ultra-precision machine tool [6]. Based on the results of the local sensitivity analysis, they were able to slightly reduce the key error components, which made it easier to control the accuracy of the machine tool [6]. Cheng et al. considered the stochastic characteristic of the geometric errors and employed Sobol's global sensitivity analysis method to identify the crucial geometric errors of a machine tool, which is helpful for improving the machining accuracy of multi-axis machine tools [7]. De-Lataliade et al. developed a method based on Monte study.
Carlo simulations (MCS) for estimating the reliability sensitivity [8]. Xiao et al. considered both epistemic and aleatory uncertainties in their reliability sensitivity analysis and proposed a unified reliability sensitivity estimation method for both epistemic and aleatory uncertainties by integrating the principles of a p-box, interval arithmetic, FORM, MCS, and weighted regression [28]. Guo and Du proposed a sensitivity analysis method for a mix of random and interval variables and defined six sensitivity indices for evaluating the sensitivity of the average reliability and reliability bounds with respect to the averages and widths of the intervals [13]. A sensitivity analysis of the geometric errors allows to identify the most critical geometric errors and then to strictly control them, thereby significantly improving the machining accuracy of the machine tool $[24,27]$

Improving the machining accuracy reliability of machine tools is an important goal for both manufacturers and users, and two tasks are usually involved to accomplish it: 1) to express and measure the machine accuracy reliability of the machine tool; 2) to identify the most critical geometric errors that most strongly affect the machining accuracy reliability of each failure mode. In this study, the sensitivity analysis was used to provide information for the reliability-based design based on solving the integral of the failure probability.

The paper is structured as follows: Section 2 deals with the modeling of the volumetric machining accuracy with consideration of the geometric error. The machining accuracy reliability analysis based on the Fast Markov chain simulation method is presented in Section 3. The sensitivity analysis based on the integration of the failure probability to identify the critical geometric errors is presented in Section 4 . In Section 5, the results of the experimental validation are discussed. In this work, a vertical machining center was selected as an example to validate the proposed analysis method. The conclusions are presented in Section 6.

\section{Volumetric error modeling by MBS theory}

In this research, a 4-axis CNC machine tool, whose wire frame structure model is shown in Fig.1, was chosen as an example to demonstrate the core concepts of the proposed methods, and its main technical parameters are listed in Table 1. For a 4-axis machine tool, there are 24 position-dependent geometric errors and 5 position-independent geometric errors when the machine tool is modeled as a set of rigid bodies according to MBS theory. The different geometric errors are listed in Table 2.

Table 1. Main technical parameters of the 4-axis CNC machine tool used as an example in this

\begin{tabular}{|c|c|c|}
\hline \multicolumn{2}{|r|}{ Configuration of the machine tool modules } & Parameters \\
\hline \multirow{3}{*}{ Workbench } & Dimensions & $2-630 \mathrm{~mm} \times 630 \mathrm{~mm}$ \\
\hline & Maximum weight of the workpiece & $1200 \mathrm{~kg}$ \\
\hline & Minimum indexing angle of the workbench & $0.001^{\circ}$ \\
\hline \multirow{4}{*}{ Working range } & Range in X-direction & $1000 \mathrm{~mm}$ \\
\hline & Range in Y-direction & $900 \mathrm{~mm}$ \\
\hline & Range in Z-direction & $900 \mathrm{~mm}$ \\
\hline & Range of motion for the rotation around the A-axis & $360^{\circ}$ \\
\hline
\end{tabular}

\subsection{Topological structure and geometric errors}

This 4-axis machine tool has four slides that can be moved relative to each other. The two other bodies that are fixed to the machine are the tool and the workpiece. Table 3 illustrates the degrees of freedom between each pair of bodies with respect to the constraints, where " 0 " means no degree of freedom and"1" means one degree of freedom.

Based on MBS theory, various parts of the machine can be de- 


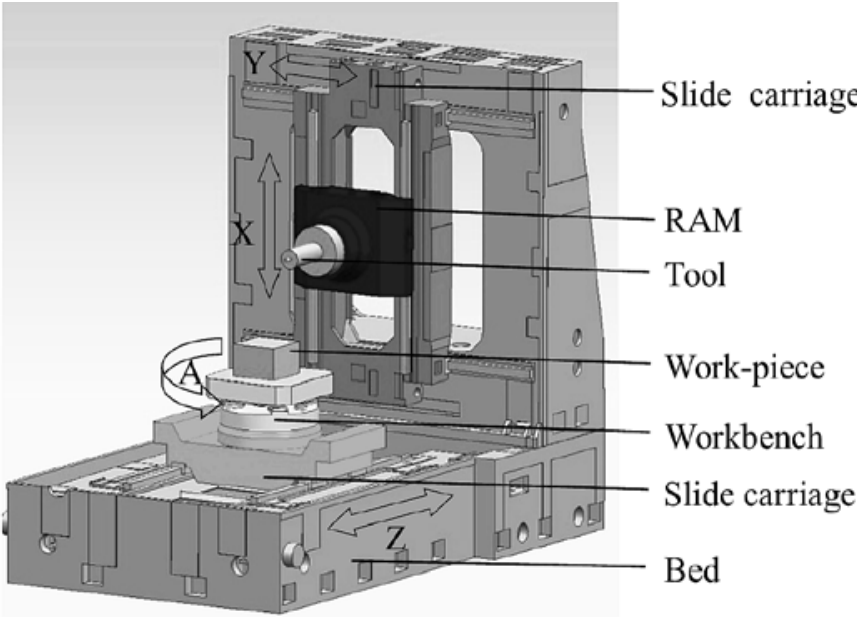

Fig. 1. Schematic illustration of the 4-axis horizontal precision machining center used as an example in this study.

Table 2. Geometric errors for the horizontal precision machining center

\begin{tabular}{|c|c|c|}
\hline Axis & Error term & $\begin{array}{r}\text { Sym- } \\
\text { bol }\end{array}$ \\
\hline \multirow[t]{6}{*}{$\mathrm{X}$-axis } & Positioning error & $\Delta x_{X}$ \\
\hline & $Y$-direction component of the straightness error & $\Delta y_{X}$ \\
\hline & $X$-direction component of the straightness error & $\Delta z_{X}$ \\
\hline & Rolling error & $\Delta a_{x}$ \\
\hline & Britain swing error & $\Delta \beta_{X}$ \\
\hline & Yaw error & $\Delta \gamma_{X}$ \\
\hline \multirow[t]{6}{*}{ Y-axis } & $X$-direction component of the straightness error & $\Delta x_{Y}$ \\
\hline & Positioning error & $\Delta y_{Y}$ \\
\hline & $Z$-direction component of the straightness error & $\Delta z_{Y}$ \\
\hline & Rolling error & $\Delta a_{Y}$ \\
\hline & Britain swing error & $\Delta \beta_{Y}$ \\
\hline & Yaw error & $\Delta \gamma_{Y}$ \\
\hline \multirow[t]{6}{*}{ Z-axis } & $X$-direction component of the straightness error & $\Delta x_{Y}$ \\
\hline & $Y$-direction component of the straightness error & $\Delta y_{z}$ \\
\hline & Positioning error & $\Delta z_{Z}$ \\
\hline & Rolling error & $\Delta a_{z}$ \\
\hline & Britain swing error & $\Delta \beta_{Z}$ \\
\hline & Yaw error & $\Delta \gamma_{Z}$ \\
\hline \multirow[t]{6}{*}{ A-axis } & Run out error of the A-axis & $\Delta x_{A}$ \\
\hline & Run out error in Y-direction & $\Delta y_{A}$ \\
\hline & Run out error in Z-direction & $\Delta z_{A}$ \\
\hline & Angular error around A-axis & $\Delta a_{A}$ \\
\hline & Angular error around $Y$-axis & $\Delta \beta_{A}$ \\
\hline & Angular error around Z-axis & $\Delta \gamma_{A}$ \\
\hline \multirow[t]{5}{*}{$\begin{array}{l}\text { Orientation } \\
\text { error }\end{array}$} & $X, Y$-axis perpendicularity error & $\Delta \gamma_{X Y}$ \\
\hline & $X, Z$-axis perpendicularity error & $\Delta \beta_{X Z}$ \\
\hline & $Y, Z$-axis perpendicularity error & $\Delta a_{Y Z}$ \\
\hline & $\begin{array}{l}\text { Parallelism of the } \mathrm{X} \text {-axis and the A-axis in the } \\
\text { Z-direction }\end{array}$ & $\Delta \beta_{Z A}$ \\
\hline & $\begin{array}{l}\text { Parallelism of the } \mathrm{X} \text {-axis and the A-axis in the } \\
\text { Y-direction }\end{array}$ & $\Delta \gamma_{Y A}$ \\
\hline
\end{tabular}

Table 3. Degrees of freedom of the different two-body pairs of the precision horizontal machining center.

\begin{tabular}{||c|c|c|c|c|c|c||}
\hline \multirow{2}{*}{ Adjacent bodies } & \multicolumn{7}{|c|}{ Directions } \\
\cline { 2 - 7 } & $\mathrm{X}$ & $\mathrm{Y}$ & $\mathrm{Z}$ & $\mathrm{a}$ & $\beta$ & $\mathrm{Y}$ \\
\hline $0-1$ & 0 & 1 & 0 & 0 & 0 & 0 \\
\hline $1-2$ & 1 & 0 & 0 & 0 & 0 & 0 \\
\hline $2-3$ & 0 & 0 & 0 & 0 & 0 & 0 \\
\hline $0-4$ & 0 & 0 & 1 & 0 & 0 & 0 \\
\hline $4-5$ & 0 & 0 & 0 & 1 & 0 & 0 \\
\hline $5-6$ & 0 & 0 & 0 & 0 & 0 & 0 \\
\hline
\end{tabular}

scribed just as an arbitrary classical body in terms of the geometric structure, and the machine tool can be treated as a MBS[17, 25].

As shown in Fig. 2, the 4-axis machine tool can be described as a structure with a double-stranded topology in which the first branch is composed of the bed, the slide carriage (Y-axis), the RAM (X-axis) and the tool. The second branch is composed of the bed, the slide carriage ( $\mathrm{Z}$-axis), the workbench (A-axis), and the workpiece. The bed is set as the inertial reference frame and denoted as body $\mathrm{B}_{0}$, and the slide carriage (Y-axis) is denoted as body $\mathrm{B}_{1}$. According to the natural growth sequence, the bodies are sequentially numbered along the direction away from the body $\mathrm{B}_{1}$ from one branch to the other branch [11]. Fig. 2 illustrates the topology diagram for the machine tool. Table 4 shows the lower body array for the selected precision horizontal machining center.

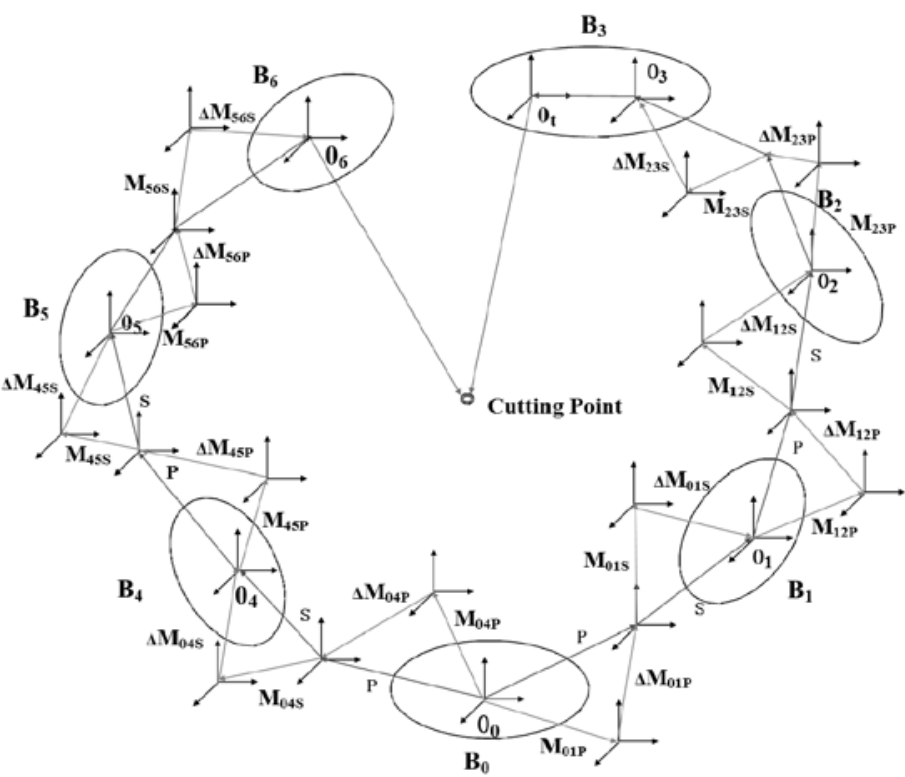

Fig. 2 Topological graph for the precision horizontal machining center. $B_{0^{-}}$ bed; $B_{1}$-slide carriage (Y-axis); $B_{2}-R A M\left(X\right.$-axis); $B_{3}$-tool; $B_{4}$-Slide carriage (Z-axis); $B_{5}$-workbench (A-axis); $B_{6}$-workpiece

A rigid solid body has six degrees of freedom. These six coordinates uniquely specify the position of a rigid body in 3D space[2]. Each body $B_{i}$ has 6 independent geometric errors $\Delta x_{h}, \Delta y_{h}, \Delta z_{h}$, $\Delta \alpha_{h}, \Delta \beta_{h}$ and $\Delta \gamma_{h} \cdot \Delta x_{h}, \Delta y_{h}$ and $\Delta z_{h}$ are translational errors. $\Delta \alpha_{h}, \Delta \beta_{h}$ and $\Delta \gamma_{h}$ are rotational errors and are referred to as pitch, roll and yaw. The subscript $h$ denotes the direction of motion, i.e., either $\mathrm{X}, \mathrm{Y}, \mathrm{Z}$ or $\mathrm{A}$. There are five squareness errors, i.e., $\Delta \gamma_{X Y}, \Delta \beta_{X Z}$ , $\Delta \alpha_{Y Z}, \Delta \gamma_{Y A}$ and $\Delta \beta_{Z A}$ between the motion axis. 
Table 4. Lower body array for the precision horizontal machining center.

\begin{tabular}{||l|l|l|l|l|l|l||}
\hline \hline Classical Body $j$ & 1 & 2 & 3 & 4 & 5 & 6 \\
\hline & 1 & 2 & 3 & 4 & 5 & 6 \\
\hline & 0 & 1 & 2 & 0 & 4 & 5 \\
\hline & 0 & 0 & 1 & 0 & 0 & 4 \\
\hline & 0 & 0 & 0 & 0 & 0 & 0 \\
\hline
\end{tabular}

Table 5. Characteristic matrices for the precision horizontal machining center

\subsection{Generalized coordinates and characteristic matrixs}

In order to normalize and make the machine tool accuracy modeling more convenient, special notations and conventions are needed for the coordinate system. The conventions used here are as follows: (1) Right-handed Cartesian coordinate systems were established for all the inertial components and the moving parts. These coordinates are generalized coordinates; the coordinate system on the inertial body is referred to as the reference coordinate system, and the coordinate systems on the other moving bodies are referred to as the moving co-

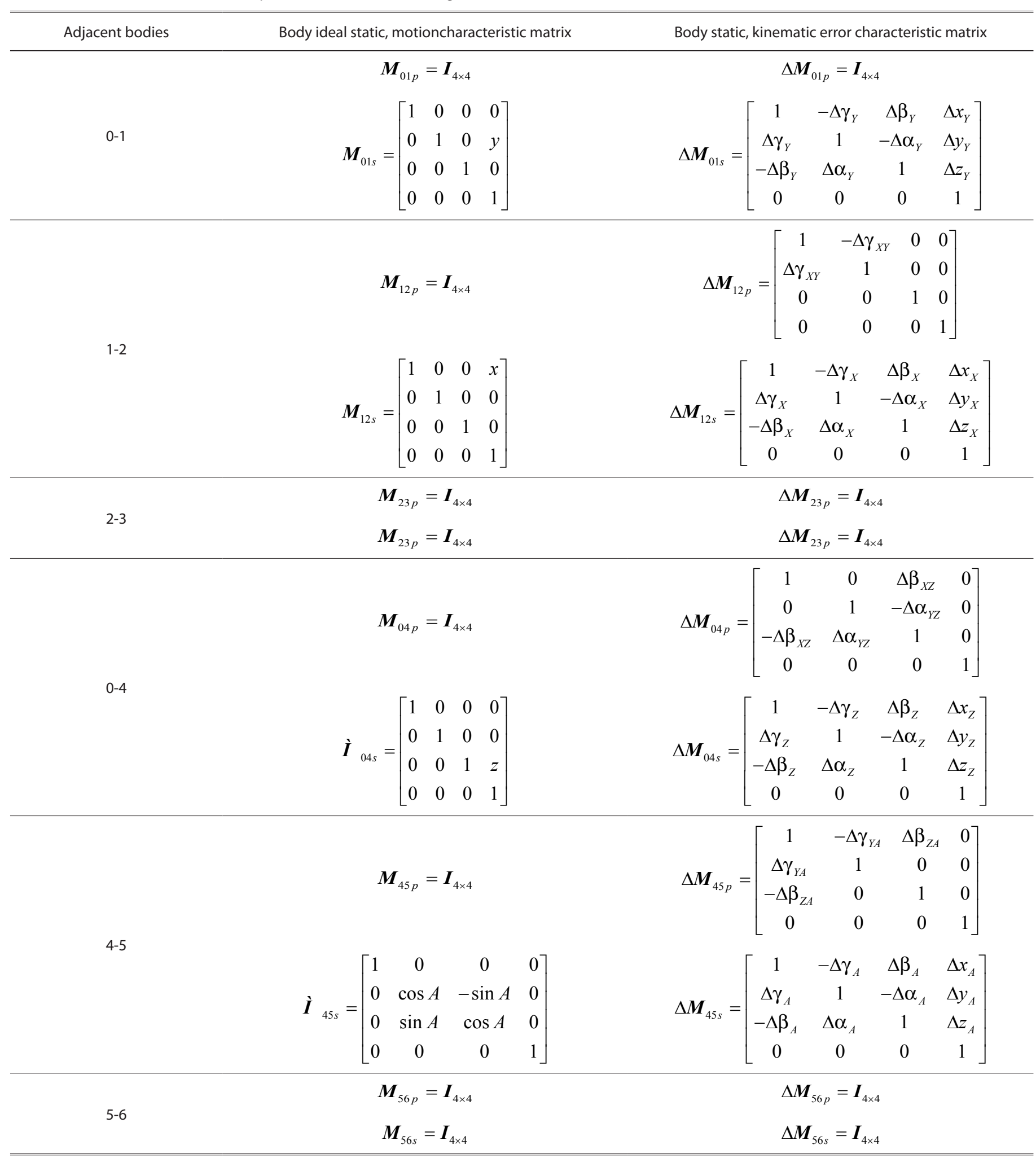


ordinate systems. (2) Each coordinate system's X-, Y-, Z-axis should be parallel to the X-, Y-, Z-axis of the other coordinate systems [23].

In MBS theory, the relation between the classical bodies of MBS can be expressed bymatrices. The characteristic matrices established for the selected machining center are listed in Table 5 .

The coordinate of the tool forming point in the coordinate system of the tool is:

$$
\boldsymbol{P}_{t}=\left[P_{t x}, P_{t y}, P_{t z}, 1\right]^{\mathrm{T}}
$$

and the coordinate of the workpiece forming point in the coordinate system of the workpiece can be written as:

$$
\boldsymbol{P}_{w}=\left[P_{w x}, P_{w y}, P_{w z}, 1\right]^{\mathrm{T}}
$$

Ideally, the machine tool is without error; the tool forming point and the workpiece forming point will overlap together. As a result, the constraint equation for precision finishing under ideal conditions is given by:

$$
\left[\prod_{k=n, L^{n}(t)=0}^{k=1} \boldsymbol{M}_{L^{k}(t) L^{L^{-1}}(t) p} \boldsymbol{M}_{L^{k}(t) L^{k-1}(t) s}\right] \boldsymbol{P}_{t}=\left[\prod_{u=n, L^{n}(w)=0}^{u=1} \boldsymbol{M}_{L^{u}(w) L^{u-1}(w) p} \boldsymbol{M}_{L^{u}(w) L^{u-1}(w) s}\right] \boldsymbol{P}_{\text {wideal }}
$$

By rearranging the terms, Eq. (3) can be rewritten as follows:

$$
\boldsymbol{P}_{\text {wideal }}=\left[\prod_{u=n, L^{n}(w)=0}^{u=1} \boldsymbol{M}_{L^{u}(w)^{u^{-1}}(w) p} \boldsymbol{M}_{L^{u}(w) L^{u-1}(w) s}\right]^{-1}\left[\prod_{k=n, L^{n}(t)=0}^{k=1} \boldsymbol{M}_{L^{k}(t) L^{k-1}(t) p} \boldsymbol{M}_{L^{k}(t) L^{k-1}(t) s}\right] \boldsymbol{P}_{t}
$$

The machining accuracy is finally related to the relative displacement error between the tool forming points of the machine and the workpiece. The constraint equation for precision finishing under actual conditions can be written as:

$$
\begin{aligned}
\boldsymbol{P}_{\text {wactual }} & =\left[\prod_{u=n, L^{n}(w)=0}^{u=1} \boldsymbol{M}_{L^{u}(w) L^{u-1}(w) p} \Delta \boldsymbol{M}_{L^{u}(w) L^{u-1}(w) p} \boldsymbol{M}_{L^{u}(w) L^{u-1}(w) s} \Delta \boldsymbol{M}_{L^{u}(w) L^{u-1}(w) s}\right]^{-1} \\
& \times\left[\prod_{k=n, L^{n}(t)=0}^{k=1} \boldsymbol{M}_{L^{k}(t) L^{k-1}(t) p} \Delta \boldsymbol{M}_{L^{k}(t) L^{k-1}(t) p} \boldsymbol{M}_{L^{k}(t) L^{k-1}(t) s} \Delta \boldsymbol{M}_{L^{k}(t) L^{k-1}(t) s}\right] \boldsymbol{P}_{t}
\end{aligned}
$$

The comprehensive volumetric error caused by the gap between the actual forming point and the ideal forming point can be expresses as:

$$
\begin{aligned}
\boldsymbol{E} & =\left[\prod_{u=n, L^{n}(w)=0}^{u=1} \boldsymbol{M}_{L^{u}(w) L^{u-1}(w) p} \Delta \boldsymbol{M}_{L^{u}(w) L^{u-1}(w) p} \boldsymbol{M}_{L^{u}(w) L^{u-1}(w) s} \Delta \boldsymbol{M}_{L^{u}(w) L^{u-1}(w) s}\right] \boldsymbol{P}_{w i d e a l} \\
& -\left[\prod_{k=n L^{n}(t)=0}^{k=1} \boldsymbol{M}_{L^{k}(t) L^{k-1}(t) p} \Delta \boldsymbol{M}_{L^{k}(t) L^{k-1}(t) p} \boldsymbol{M}_{L^{k}(t) L^{k-1}(t) s} \Delta \boldsymbol{M}_{L^{k}(t) L^{k-1}(t) s}\right] \boldsymbol{P}_{t}
\end{aligned}
$$

The comprehensive volumetric error mode of the horizontal precision machining center can be obtained from the characteristic matrices in Table 4 and Eq. (6). Similarly, the general volumetric error model for the machine tool can be established as follows:

$$
\boldsymbol{E}=\boldsymbol{E}\left(\boldsymbol{G}, \boldsymbol{P}_{t}, \boldsymbol{P}\right)
$$

where $\boldsymbol{E}=\left[E_{X}, E_{Y}, E_{Z}, 0\right]^{\mathrm{T}}$ is the volumetric error vector; $\boldsymbol{G}=\left[g_{1}, g_{2}, \ldots, g_{29}\right]^{T}$ is the vector consisting of 29 geometric errors, and $\Delta x_{X}, \Delta y_{X}, \Delta z_{X}, \Delta \alpha_{X}, \Delta \beta_{X}, \Delta \gamma_{X}, \Delta x_{Y}, \Delta y_{Y}, \Delta z_{Y}, \Delta \alpha_{Y}, \Delta \beta_{Y}$, $\Delta \gamma_{Y}, \Delta x_{Z}, \Delta y_{Z}, \Delta z_{Z}, \Delta \alpha_{Z}, \Delta \beta_{Z}, \Delta \gamma_{Z}, \Delta x_{A}, \Delta y_{A}, \Delta z_{A}, \Delta \alpha_{A}, \Delta \beta_{A}$ $, \Delta \gamma_{A}, \Delta \gamma_{X Y}, \Delta \beta_{X Z}, \Delta \alpha_{Y Z}, \Delta \gamma_{Y A}, \Delta \beta_{Z A}=g_{1}, g_{2}, g_{3}, g_{4}, g_{5}, g_{6}$, $g_{7}, g_{8}, g_{9}, g_{10}, g_{11}, g_{12}, g_{13}, g_{14}, g_{15}, g_{16}, g_{17}, g_{18}, g_{19}, g_{20}, g_{21}$, $g_{22}, g_{22}, g_{23}, g_{24}, g_{25}, g_{26}, g_{27}, g_{28}, g_{29} ; \quad \mathbf{P}=[x, y, z, 0]^{\mathrm{T}}$ represents the position vector of the motion axes of the machine center.

\section{Machining accuracy reliability analysis based on Fast Markov Chain simulations}

The machining accuracy reliability refers to the ability of the machine tool to perform at its specified machining accuracy under the stated conditions for a given period of time. In general, the volumetric machining errors can be decomposed into the corresponding X-, Y-, $Z$-direction components, and if the machining accuracy is lower than the specified requirement in the X-, Y- and Z-direction, respectively, the machining accuracy can be considered to be violated.

\subsection{Failure mode and failure probability}

The comprehensive volumetric error mode of the machine center can be written as:

$$
\mathbf{E}=\mathbf{E}(\mathbf{G})=\left[E_{X}(\mathbf{G}), E_{Y}(\mathbf{G}), E_{Z}(\mathbf{G}), 0\right]^{\mathrm{T}}
$$

The maximum permissible volumetric error of the machine tool is $\mathbf{e}=\left(e_{X}, e_{Y}, e_{Z}, 0\right)^{\mathrm{T}}$, where $e_{X}, e_{Y}, e_{Z}$ indicates the maximum permissible volumetric error in X-, Y-, Z-direction, respectively, and the function matrix can be expressed as follow:

$\mathbf{F}=[\mathbf{E}-\mathbf{e}]=\left[E_{X}(\mathbf{G})-e_{X}, E_{Y}(\mathbf{G})-e_{Y}, E_{Z}(\mathbf{G})-e_{Z}, 0\right]^{\mathrm{T}}==\left[\begin{array}{c}H_{X}(\mathbf{G}) \\ H_{Y}(\mathbf{G}) \\ H_{Z}(\mathbf{G}) \\ 0\end{array}\right]$

The machining accuracy of the NC machine tool shows the following seven failure modes:

$$
\begin{aligned}
& M_{1}=\left\{H_{X} \geq 0, H_{Y} \leq 0 \text { and } H_{Z} \leq 0\right\} \\
& M_{2}=\left\{H_{X} \leq 0, H_{Y} \geq 0 \text { and } H_{Z} \leq 0\right\} \\
& M_{3}=\left\{H_{X} \leq 0, H_{Y} \leq 0 \text { and } H_{Z} \geq 0\right\} \\
& M_{4}=\left\{H_{X} \geq 0, H_{Y} \geq 0 \text { and } H_{Z} \leq 0\right\} \\
& M_{5}=\left\{H_{X} \geq 0, H_{Y} \leq 0 \text { and } H_{Z} \geq 0\right\} \\
& M_{6}=\left\{H_{X} \leq 0, H_{Y} \geq 0 \text { and } H_{Z} \geq 0\right\} \\
& M_{7}=\left\{H_{X} \geq 0, H_{Y} \geq 0 \text { and } H_{Z} \geq 0\right\}
\end{aligned}
$$


In Eqs.(10) to (12), $M_{1} \quad M_{2}$ and $M_{3}$ represent the cases where the machining accuracy of the machine tool in either the X-, Y- or Z-direction cannot meet the maximum permissible volumetric error.

In Eqs.(13) to (15), $M_{4} \quad M_{5}$ and $M_{6}$ represent the cases where the machining accuracy of the machine tool cannot meet the maximum permissible volumetric error in two of the three directions. And In

Eq.16, $M_{7}$ represent the case where the machining accuracy of the machine tool cannot meet the maximum permissible volumetric error in all of the three directions. lows:

The failover domains for each of the failure modes are as fol-

$$
\begin{aligned}
& F_{1}=\left\{\mathbf{G}: \mathbf{G} \in H_{X}(\mathbf{G}) \geq 0, \mathbf{G} \in H_{Y}(\mathbf{G}) \leq 0 \text { and } \mathbf{G} \in H_{Z}(\mathbf{G}) \leq 0\right\} \\
& F_{2}=\left\{\mathbf{G}: \mathbf{G} \in H_{X}(\mathbf{G}) \leq 0, \mathbf{G} \in H_{Y}(\mathbf{G}) \geq 0 \text { and } \mathbf{G} \in H_{Z}(\mathbf{G}) \leq 0\right\} \\
& F_{3}=\left\{\mathbf{G}: \mathbf{G} \in H_{X}(\mathbf{G}) \leq 0, \mathbf{G} \in H_{Y}(\mathbf{G}) \leq 0 \text { and } \mathbf{G} \in H_{Z}(\mathbf{G}) \geq 0\right\}(19) \\
& F_{4}=\left\{\mathbf{G}: \mathbf{G} \in H_{X}(\mathbf{G}) \geq 0, \mathbf{G} \in H_{Y}(\mathbf{G}) \geq 0 \text { and } \mathbf{G} \in H_{Z}(\mathbf{G}) \leq 0\right\} \\
& F_{5}=\left\{\mathbf{G}: \mathbf{G} \in H_{X}(\mathbf{G}) \geq 0, \mathbf{G} \in H_{Y}(\mathbf{G}) \leq 0 \text { and } \mathbf{G} \in H_{Z}(\mathbf{G}) \geq 0\right\} \\
& F_{6}=\left\{\mathbf{G}: \mathbf{G} \in H_{X}(\mathbf{G}) \leq 0, \mathbf{G} \in H_{Y}(\mathbf{G}) \geq 0 \text { and } \mathbf{G} \in H_{Z}(\mathbf{G}) \geq 0\right\} \\
& F_{7}=\left\{\mathbf{G}: \mathbf{G} \in H_{X}(\mathbf{G}) \geq 0, \mathbf{G} \in H_{Y}(\mathbf{G}) \geq 0 \text { and } \mathbf{G} \in H_{Z}(\mathbf{G}) \geq 0\right\}
\end{aligned}
$$

In the reliability analysis of the machining accuracy, the failure probability $P$ can be defined as the integral of the joint probability density function $f(\mathbf{G})$ for geometric errors in the failover domain $F$ , so the failure probabilities of the different failure modes can be expressed as:

$$
P_{F}^{(i)}=P\left\{\mathbf{G} \in F_{i}\right\}=\int \cdots \int_{F_{i}} f(\mathbf{G}) \mathrm{d} \mathbf{G}
$$

where, $i=1,2 \ldots 7$, and $i$ is the number of the failure modes.

The overall failure probability $P_{F}$ of the machining accuracy can then be derived from basic principles of probability theory and statistics as follows:

$$
P_{F}=P_{F}^{(1)}+P_{F}^{(2)}+P_{F}^{(3)}+P_{F}^{(4)}+P_{F}^{(5)}+P_{F}^{(6)}+P_{F}^{(7)}
$$

\subsection{Conversion of the correlated normal variables into inde- pendent standard normal variables}

During actual processing, the geometric errors of the machine tool are correlated to each other and the effect of this correlation on the failure probability of the machining accuracy cannot be ignored. For a practical reliability analysis of the machining accuracy, in order to account for the actual situation, the correlation between the geometric errors of the machine tool must be taken into account. Therefore, the correlated geometric errors were first converted into independent standard normal random variables. Then, the reliability analysis method in independent space was used to determine the failure probability of the machining accuracy.
The $n$ geometric errors of the machine tool can be represented as n-dimensional normal random variables $\mathbf{G}=\left(g_{1}, g_{2}, \ldots g_{n}\right)^{\mathrm{T}}$. Because the $g$ eometric errors are correlated, the probability density function $f(\mathbf{G})$ of the geometric error vector $\mathbf{G}$ can be expressed as:

$$
f(\mathbf{G})=(2 \pi)^{-\frac{n}{2}}\left|\mathbf{C}_{\mathbf{G}}\right|^{-\frac{1}{2}} \exp \left[-\frac{1}{2}\left(\mathbf{G}-\mu_{\mathbf{G}}\right)^{\mathrm{T}} \mathbf{C}_{\mathbf{G}}^{-1}\left(\mathbf{G}-\mu_{\mathbf{G}}\right)\right]
$$

where:

$\mathbf{C}_{\mathbf{G}}=\left[\begin{array}{ccccc}\sigma_{g_{1}}^{2} & \rho_{g_{1} g_{2}} \sigma_{g_{1}} \sigma_{g_{2}} & \rho_{g_{1} g_{3}} \sigma_{g_{1}} \sigma_{g_{3}} & \cdots & \rho_{g_{1} g_{n}} \sigma_{g_{1}} \sigma_{g_{n}} \\ \rho_{g_{1} g_{2}} \sigma_{g_{1}} \sigma_{g_{2}} & \sigma_{g_{2}}^{2} & \rho_{g_{2} g_{3}} \sigma_{g_{2}} \sigma_{g_{3}} & \cdots & \rho_{g_{2} g_{n}} \sigma_{g_{2}} \sigma_{g_{n}} \\ \rho_{g_{1} g_{3}} \sigma_{g_{1}} \sigma_{g_{3}} & \rho_{g_{2} g_{3}} \sigma_{g_{2}} \sigma_{g_{3}} & \sigma_{g_{3}}^{2} & & \rho_{g_{3} g_{n}} \sigma_{g_{2}} \sigma_{g_{n}} \\ \vdots & \vdots & \vdots & & \vdots \\ \rho_{g_{1} g_{n}} \sigma_{g_{1}} \sigma_{g_{n}} & \rho_{g_{2} g_{n}} \sigma_{g_{2}} \sigma_{g_{n}} & \rho_{g_{3} g_{n}} \sigma_{g_{2}} \sigma_{g_{n}} & \cdots & \sigma_{g_{n}}^{2}\end{array}\right]$

represents the covariance matrix of the geometric errors $\mathbf{G} ; \mathbf{C}_{\mathbf{G}}^{-1}$ is the inverse matrix of $\mathbf{C}_{\mathbf{G}} ;\left|\mathbf{C}_{\mathbf{G}}\right|$ is the determinant of $\mathbf{C}_{\mathbf{G}}$; and $\mu_{\mathbf{G}}=\left(\mu_{g_{1}}, \mu_{g_{2}}, \ldots \mu_{g_{n}}\right)^{\mathrm{T}}$ is the vector composed of the mean values of the geometric errors, $\mu_{g_{i}}$ and $\sigma_{g_{i}}$ represent the mean value and the variance of geometric error $g_{i}(i=1,2,3, \cdots, n)$, and $\rho_{g_{i} g_{j}}$ is the correlation coefficient of $g_{i}$ and $g_{j}$.

According to the basic principles of linear algebra, there must be an orthogonal matrix A to convert the correlated normal variables $\mathbf{G}=\left(g_{1}, g_{2}, \cdots g_{n}\right)^{\mathrm{T}} \quad$ into independent normal variables $\mathbf{y}=\left(y_{1}, y_{2}, \cdots y_{n}\right)^{\mathrm{T}}$ as follows :

$$
f_{Y}(\mathbf{y})=f_{\mathbf{G}}\left(\mathbf{A}^{-1} \mathbf{y}+\mu_{\mathbf{G}}\right)=(2 \pi)^{-\frac{n}{2}}\left(\lambda_{1} \lambda_{2} \cdots \lambda_{n}\right)^{-\frac{1}{2}} \exp \left(-\frac{1}{2} \sum_{i=1}^{n} \frac{y_{i}^{2}}{\lambda_{i}}\right)
$$

and:

$$
\boldsymbol{y}=\mathbf{A}\left(\mathbf{G}-\boldsymbol{\mu}_{\mathbf{G}}\right), y_{i} \sim N\left(0, \lambda_{i}\right)
$$

where, $\lambda_{1}, \lambda_{2}, \cdots \lambda_{n}$ are the eigenvalues of the covariance matrix $\mathbf{C}_{\mathbf{G}}$. Furthermore, the column vectors of the orthogonal matrix $\mathbf{A}$ are equal to the orthogonal eigenvectors of the covariance matrix $\mathbf{C}_{\mathbf{G}}$.

Based on the linear transformation $\boldsymbol{y}=\mathbf{A}\left(\mathbf{G}-\mu_{\mathbf{G}}\right)$, the correlated normal variables $\mathbf{G}=\left(g_{1}, g_{2}, \cdots g_{n}\right)^{\mathrm{T}}$ were converted to the independent normal variables $\mathbf{y}=\left(y_{1}, y_{2}, \cdots y_{n}\right)^{\mathrm{T}}$. Then, the independent normal variables $\mathbf{y}=\left(y_{1}, y_{2}, \cdots y_{n}\right)^{\mathrm{T}}$ were converted into independent standard normal random variables $\mathbf{u}=\left(u_{1}, u_{2}, \cdots u_{n}\right)^{\mathrm{T}}$ by using the following function.

$$
u_{i}=\frac{\mathbf{y}_{i}-\mu_{y_{i}}}{\sigma_{y_{i}}}=\frac{\mathbf{y}_{i}}{\sqrt{\lambda_{i}}}(i=1,2, \cdots n)
$$


Next, the failover domain $F(\mathbf{G})$ and the performance function $H(\mathbf{G})$ in the related space were converted to the failover domain $F(\mathbf{u})$. Finally, the failure probabilities of each failure modes can be rewritten as:

$$
P_{F}^{(i)}=\int \cdots \int_{F_{i}(\mathbf{G})} f_{G}(\mathbf{G}) d \mathbf{G}=\int \cdots \int_{F_{i}(\mathbf{y})} f_{Y}(\mathbf{y}) d \mathbf{y}=\int \cdots \int_{F_{i}(\mathbf{u})} f_{U}(\mathbf{u}) d(\mathbf{u})
$$

\subsection{Fast Markov Chain simulation method for estimating the failure probability}

There are many different methods to calculate the reliability of the machining accuracy based on numerical simulations which can be used for either analyzing the single failure mode-reliability or the multiple failure modes-reliability. However, the Markov chain method has so far not been used to analyze the reliability of the machining accuracy.

Because samples in the failover domain can be simulated efficiently by adopting the Markov chain method, for the general nonlinear limit state equation $H_{U}(\mathbf{u})=H_{G}(\mathbf{G})=\left\{\begin{array}{l}H_{X}(\mathbf{G})=0 \\ H_{Y}(\mathbf{G})=0 \\ H_{Z}(\mathbf{G})=0\end{array}\right.$, the Markov chain method can be used to determine the most probable failure point in the failover domain which is referred to as the design point. Through the design point, the linear limit state equation

$L(\mathbf{u})=0$ which has the same design point has the non-linear limit state equation $H_{U}(\mathbf{u})=H_{G}(\mathbf{G})=\left\{\begin{array}{l}H_{X}(\mathbf{G})=0 \\ H_{Y}(\mathbf{G})=0 \text { can be obtained in the } \\ H_{Z}(\mathbf{G})=0\end{array}\right.$ independent standard normal space.

Based on the multiplication theorem in probability theory, the following two equations can then be established.

$$
\begin{aligned}
& P\left\{F_{H} \cap F_{L}\right\}=P\left\{F_{H}\right\} P\left\{F_{L} \mid F_{H}\right\} \\
& P\left\{F_{H} \cap F_{L}\right\}=P\left\{F_{L}\right\} P\left\{F_{H} \mid F_{L}\right\}
\end{aligned}
$$

where,

$$
F_{H}=\left\{\mathbf{u}: \mathbf{u} \rightarrow \mathbf{G} \in F_{i}\right\},
$$$$
F_{L}=\{\mathbf{u}: L(\mathbf{u}) \leq 0\},
$$

$P\left\{F_{L}\right\}=P\{L(\mathbf{u}) \leq 0\} \quad$ and $\quad P\left\{F_{H}\right\}=P\left\{F_{i}\right\} . \quad P\left\{F_{L} \mid F_{H}\right\} \quad$ and $P\left\{F_{H} \mid F_{L}\right\}$ are conditional probabilities.

Thus, the failure probability $P_{F}$ can be expressed as follows:

$$
P_{F}^{(i)}=P\left(F_{i}\right)=P\left\{F_{H}\right\}=P\left\{F_{L}\right\} \frac{P\left\{F_{H} \mid F_{L}\right\}}{P\left\{F_{L} \mid F_{H}\right\}}
$$

where, $\frac{P\left\{F_{H} \mid F_{L}\right\}}{P\left\{F_{L} \mid F_{H}\right\}}$ can be defined as the scaling factor $S$ :

$$
S=\frac{P\left\{F_{H} \mid F_{L}\right\}}{P\left\{F_{L} \mid F_{H}\right\}}
$$

Then Eq.(35) can be simplified as follows:

$$
P_{F}^{(i)}=P\left\{F_{L}\right\} \cdot S
$$

The probability density function of the samples which belong to the failover domain $F_{H}$ can be expressed as follows:

$$
q_{H}\left(\mathbf{u} \mid F_{H}\right)=\frac{I_{H}(\mathbf{u}) f_{U}(\mathbf{u})}{P_{H}}
$$

where, $I_{H}(\mathbf{u})$ is the indicator function of the non-linear performance function $H(\mathbf{u})$, and

$$
I_{H}(\mathbf{u})= \begin{cases}1, & H(\mathbf{u})<0 \\ 0, & H(\mathbf{u}) \geq 0\end{cases}
$$

According to the basic principles of Markov chain simulations, the transformation from one state to another state of the Markov chain is controlled by the proposal distribution function $f^{*}(\mathbf{a} \mid \mathbf{u})$. Both a symmetrical n-dimensional normal distribution and an n-dimensional uniform distribution can be used as a suggested distribution of the Markov chain. In this paper, the symmetrical n-dimensional uniform distribution was selected as the suggested distribution:

$$
f^{*}(\mathfrak{a} \mid \mathbf{u})= \begin{cases}1 / \prod_{k=1}^{n} l_{k}, & \left|\varepsilon_{k}-u_{k}\right| \leq \frac{l_{k}}{2} \\ 0, & \text { Others }\end{cases}
$$

where, $\varepsilon_{k}$ and $u_{k}$ represent the $k^{\text {th }}$ component of the n-dimensional vector $\stackrel{a}{ }$ and $\mathbf{u}$ respectively. $l_{k}$ represents the side length of the n-dimensional polyhedron in the $u_{k}$-direction, and $\mathbf{u}$ is the center of the $\mathrm{n}$-dimensional polyhedron. Furthermore, $l_{k}$ determines the maximum allowed distances from the next sample to the current sample.

Based on practical engineering experience and numerical algorithms, a point in the failover domain $F_{H}$ was selected as the initial state of the Markov chain and denoted as $u_{0}$. The $j^{\text {th }}$ state $u_{j}$ of the Markov chain was then determined by the proposal distribution function and according to the Metropolis-Hastings guidelines based on the $\mathrm{j}$-1 th state $u_{j-1}$. First, a candidate state å was obtained through the proposal distribution function $f^{*}\left(\mathfrak{a} \mid \mathbf{u}_{j-1}\right)$. Then, the ratio $r$ of the candidate state å 's conditional probability density function and the

state $\mathbf{u}_{j-1}$ 's conditional probability density function can be expressed as follows:

$$
r=q\left(\grave{a} \mid F_{H}\right) / q\left(\mathbf{u}_{j-1} \mid F_{H}\right)
$$

At last, the next state $\mathbf{u}_{j}$ was determined according to the Metropolis-Hastings guidelines: 


$$
\mathbf{u}_{j}= \begin{cases}\mathbf{a}, & \min \{1, r\}>\operatorname{random}[0,1] \\ \mathbf{u}_{j-1}, & \min \{1, r\} \leq \operatorname{random}[0,1]\end{cases}
$$

where, random $[0,1]$ represents the random number which obeys the uniform distribution in $[0,1]$.

$N_{H}$ states $\left\{\mathbf{u}_{0}, \mathbf{u}_{1}, \cdots \mathbf{u}_{N_{H}-1}\right\}$ of the Markov chain can be generated via the above method, and they are sample points of the probabil-

ity density function $q_{H}\left(\mathbf{u} \mid F_{H}\right)$. We selected the point which has the maximum value of $f_{U}(\mathbf{u})$ in the failover domain $F_{H}$ from the $N_{H}$ sample points of the probability density function $q_{H}\left(\mathbf{u} \mid F_{H}\right)$. This point is the maximum likelihood point and was denoted as $\mathbf{u}^{*}=\left(u_{1}^{*}, u_{2}^{*}, \cdots, u_{n}^{*}\right)$.

In the independent standard normal space, the linear limit state equation with the same maximum likelihood point of the failover domain $F_{H}$ can be expressed as follows:

$$
L(\mathbf{u})=\left(\mathbf{0}-\mathbf{u}^{*}\right)\left(\mathbf{u}-\mathbf{u}^{*}\right)^{\mathrm{T}}=0
$$

The corresponding probability of failure is:

$$
P\left\{F_{L}\right\}=\Phi\left(-\sqrt{\left(u_{1}^{*}\right)^{2}+\left(u_{2}^{*}\right)^{2}+\cdots+\left(u_{n}^{*}\right)^{2}}\right)
$$

where, $\Phi(\cdot)$ is the distribution function of the standard normal variable.

When plugging the $N_{H}$ sample points into Eq.(42), the number of samples falling into $F_{L}=\{\mathbf{u}: L(\mathbf{u}) \leq 0\}$ can be denoted as $N_{L \mid H}$.

Then, the estimation of the condition probability $P\left\{F_{L} \mid F_{H}\right\}$ can be written as follows:

$$
\widehat{P}\left\{F_{L} \mid F_{H}\right\}=\frac{N_{L \mid H}}{N_{H}}
$$

Similarly, the condition probability $P\left\{F_{H} \mid F_{L}\right\}$ can be obtained using the Markov chain method to simulate the sample point in the failover domain $F_{L}$. The joint probability density function of the sample points in the failover domain $F_{L}$ can be expressed as follows:

$$
q_{L}\left(\mathbf{u} \mid F_{L}\right)=\frac{I_{L}(\mathbf{u}) f_{U}(\mathbf{u})}{P_{L}}
$$

$N_{L}$ sample points in the failover domain can be obtained through the Markov chain simulations. By plugging these sample points into $H(\mathbf{u})$ and calculating the values of $H(\mathbf{u})$, the number of sample points falling into the failover domain $F_{H}=\{\mathbf{u}: H(\mathbf{u}) \leq 0\}$ can be obtained and recorded as $N_{H \mid L}$.

Then, the estimation of the condition probability $P\left\{F_{L} \mid F_{H}\right\}$ and the scaling factor $S$ can be written as follows:

$$
\begin{gathered}
\widehat{P}\left\{F_{H} \mid F_{L}\right\}=\frac{N_{H \mid L}}{N_{L}} \\
\hat{S}=\frac{\widehat{P}\left\{F_{H} \mid F_{L}\right\}}{\widehat{P}\left\{F_{L} \mid F_{H}\right\}}=\frac{N_{H \mid L}}{N_{L}} \cdot \frac{N_{H}}{N_{L \mid H}}
\end{gathered}
$$

Because the machine tool has several failure modes, the failure probability of each failure mode should be calculated individually.

Let $F_{H}=F_{i}, i=1,2, \cdots 7$, then the $P\left\{F_{L}^{(i)}\right\}$ and $S^{(i)}$ corresponding to the failure modes can be obtained through.

$$
P_{F}^{(i)}=P\left\{F_{L}^{(i)}\right\} S^{(i)} \quad i=1,2, \cdots 7
$$

The comprehensive failure probability of the machining accuracy can finally be expressed as follows:

$$
\widehat{P}_{F}=P_{F}^{(1)}+P_{F}^{(2)}+P_{F}^{(3)}+P_{F}^{(4)}+P_{F}^{(5)}+P_{F}^{(6)}+P_{F}^{(7)}
$$

\section{Machining accuracy reliability sensitivity analysis based on solving the integral of the failure prob- ability}

The machining accuracy reliability sensitivity coefficient is generally defined as the partial derivative of the failure probability for each failure mode with respect to the probability distribution parameters of the $k^{\text {th }}$ geometric error. This can be expressed as follows:

$$
\begin{aligned}
& S_{\mu_{k}}^{(i)}=\frac{\partial P_{F}^{(i)}}{\partial \mu_{k}}=\int \cdots \int_{F_{i}} \frac{\partial f(\mathbf{G})}{\partial \mu_{k}} \mathrm{~d} \mathbf{G} \\
& S_{\sigma_{k}}^{(i)}=\frac{\partial P_{F}^{(i)}}{\partial \sigma_{k}}=\int \cdots \int_{F_{i}} \frac{\partial f(\mathbf{G})}{\partial \sigma_{k}} \mathrm{~d} \mathbf{G}
\end{aligned}
$$

where, $i=1,2, \cdots, 7 ; k=1,2, \cdots, \mathrm{n}$; and $\mathrm{n}$ is the number of geometric errors. $\mu_{k}$ is the mean value of the $k^{\text {th }}$ geometric error. $\sigma_{k}$ is the standard deviation of $k^{\text {th }}$ geometric errors. $S_{\mu_{k}}^{(i)}$ is the machining accuracy reliability sensitivity about the mean value $\mu_{k}$ with respect to the failure probability for $i^{\text {th }}$ failure mode. $S_{\sigma_{k}}^{(i)}$ is the machining accuracy reliability sensitivity about the standard deviation $\sigma_{k}$ with respect to the failure probability for the $i^{\text {th }}$ failure mode.

Next, we defined the following regularized reliability sensitivity coefficients: 


$$
\begin{gathered}
S A_{\mu_{k}}^{(i)}=\frac{\partial P_{F}^{(i)}}{\partial \mu_{k}} \frac{\sigma_{k}}{P_{F}^{(i)}} \\
S A_{\sigma_{k}}^{(i)}=\frac{\partial P_{F}^{(i)}}{\partial \sigma_{k}} \frac{\sigma_{k}}{P_{F}^{(i)}}
\end{gathered}
$$

Then, we transformed Eqs.(52) and (53) into their corresponding integral form:

$$
\begin{aligned}
& S A_{\mu_{k}}^{(i)}=\int \cdots \int_{F_{i}} \frac{\sigma_{k}}{f(\mathbf{G})} \frac{\partial f(\mathbf{G})}{\partial \mu_{k}}\left(\frac{f(\mathbf{G})}{P_{F}^{(i)}}\right) \mathrm{d} \mathbf{G} \\
& S A_{\sigma_{k}}^{(i)}=\int \cdots \int_{F_{i}} \frac{\sigma_{k}}{f(\mathbf{G})} \frac{\partial f(\mathbf{G})}{\partial \sigma_{k}}\left(\frac{f(\mathbf{G})}{P_{F}^{(i)}}\right) \mathrm{d} \mathbf{G}
\end{aligned}
$$

Obviously Eq. (54) and (55) can be expressed as the mathematical expectation in the failure domain $F_{i}$ :

$$
\begin{aligned}
& S A_{\mu_{k}}^{(i)}=E_{F_{i}}\left[\frac{\sigma_{k}}{f(\mathbf{G})} \frac{\partial f(\mathbf{G})}{\partial \mu_{k}}\right] \\
& S A_{\sigma_{k}}^{(i)}=E_{F_{i}}\left[\frac{\sigma_{k}}{f(\mathbf{G})} \frac{\partial f(\mathbf{G})}{\partial \sigma_{k}}\right]
\end{aligned}
$$

where, $E_{F_{i}}[\cdot]$ is the mathematical expectation in the failure domain $F_{i}$.

Through Eqs.(29) and (30), the sample points $\left\{\mathbf{u}_{0}^{(i)}, \mathbf{u}_{1}^{(i)}, \cdots \mathbf{u}_{N_{H}-1}^{(i)}\right\}$ can be converted to $\left\{\mathbf{G}_{0}^{(i)}, \mathbf{G}_{1}^{(i)}, \cdots \mathbf{G}_{N_{H}-1}^{(i)}\right\}$ By plugging $\left\{\mathbf{G}_{0}^{(i)}, \mathbf{G}_{1}^{(i)}, \cdots \mathbf{G}_{N_{H}-1}^{(i)}\right\}$ into the following formulas, the regularized reliability sensitivity coefficients can be eventually obtained:

$$
\begin{aligned}
& \widehat{S A}_{\mu_{k}}^{(i)}=\frac{1}{N_{H}} \sum_{0}^{N_{H}-1} \frac{\sigma_{k}}{f(\mathbf{G})} \frac{\partial f(\mathbf{G})}{\partial \mu_{k}} \\
& \widehat{S A}_{\sigma_{k}}^{(i)}=\frac{1}{N_{H}} \sum_{0}^{N_{H}-1} \frac{\sigma_{k}}{f(\mathbf{G})} \frac{\partial f(\mathbf{G})}{\partial \sigma_{k}}
\end{aligned}
$$

Then, the general reliability sensitivity coefficients can be expressed as follows:

$$
S_{\mu_{k}}^{(i)}=\frac{\partial P_{F}^{(i)}}{\partial \mu_{k}}=\widehat{S A}_{\mu_{k}}^{(i)} \cdot \frac{P_{F}^{(i)}}{\sigma_{k}}
$$

$$
S_{\sigma_{k}}^{(i)}=\frac{\partial P_{F}^{(i)}}{\partial \sigma_{k}}=\widehat{S A}_{\sigma_{k}}^{(i)} \cdot \frac{P_{F}^{(i)}}{\sigma_{k}}
$$

\section{Application and improvement}

The machine tool shown in Fig.1 was selected as an example to demonstrate the method. The six position dependent geometric errors of each prismatic joint were directly measured using a dual-frequency laser interferometer[15] and an electronic level. XD sensor was used to receive and reflect the laser in the measurement process. And it was also used to detect the angle error and the straightness error of the measuring process. The squareness errors were measured using a dial indicator and a flat ruler. A photograph of the experimental setup is shown in Fig.3.

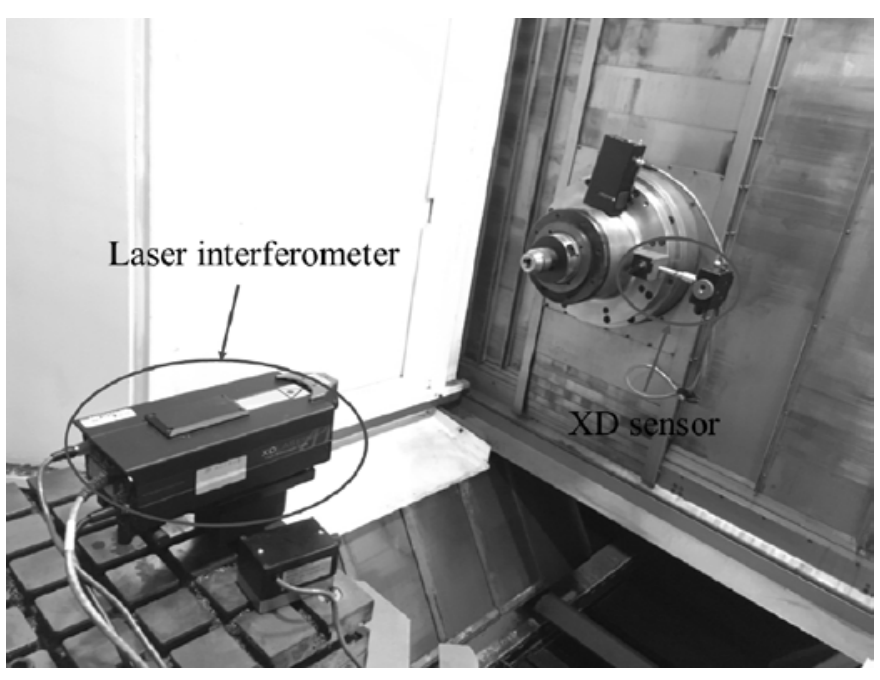

Fig. 3 Photograph of the experimental setup.

Through a statistical analysis of the obtained sample data, the probability distribution of the geometric errors can be obtained. Taking the positioning error at $\Delta x_{x}=200 \mathrm{~mm}, \mathrm{y}=400 \mathrm{~mm}, \mathrm{z}=300 \mathrm{~mm}$ as an example, the geometric error can be described by a normal distribution. Actually, the experimental results showed that each positiondependent geometric error can be described by a normal distribution [35]. Table 6 lists the values obtained for the position-independent errors. Table 7 compares the mean values $(M)$ and the variance values $(V)$ of the probability distributions used to describe the position-dependent geometric errors at $x=200 \mathrm{~mm}, y=400 \mathrm{~mm}, z=300 \mathrm{~mm}$.

Using the proposed method, the failure probabilities were calculated for each failure mode at $x=200 \mathrm{~mm}, \mathrm{y}=400 \mathrm{~mm}, \mathrm{z}=300 \mathrm{~mm}$, and the results are listed in Table 8 . The results of machining accuracy reliability sensitivity analysis are presented in Table 9.

Nine evenly spaced test points (a total of 33 test points) were selected along each body diagonal of the machine tool's working space, zas shown in Fig.4. The results of the sensitivity analysis at each test point were obtained using the method described above. Then, a sensitivity analysis for the whole working space was conducted employing the weighted average method.

The failure probability of failure mode $M_{i}$, at the test point " $j$ ", was defined as ${ }^{j} P_{F}^{(i)}$, and the failure probability of failure mode $M_{i}$ for the whole working space can be defined as $\widehat{P}_{F}^{(i)}$. Furthermore, the machining accuracy reliability sensitivity of the mean value $\mu_{k}$ of geometric error $g_{k}$ for the $i^{\text {th }}$ failure mode $M_{i}$, at the test point " $j$ ", was 
Table 6. Values obtained for the position-independent errors.

\begin{tabular}{ccc}
\hline \hline Sequence Number & Parameter & Value $(\mathrm{mm})$ \\
\hline 1 & $0.0039 / 500$ \\
2 & $0.0037 / 500$ \\
3 & $0.0037 / 500$ \\
4 & $0.012 / 300$ \\
5 & $0.012 / 300$ \\
\hline \hline
\end{tabular}

Table 7. Probability distributions of position-dependent geometric errors

\begin{tabular}{|c|c|c|c|c|}
\hline $\begin{array}{l}\text { Sequence } \\
\text { Number }\end{array}$ & $\begin{array}{l}\text { Param- } \\
\text { eter }\end{array}$ & $\begin{array}{c}\text { Probability distribu- } \\
\text { tion }\end{array}$ & $\mathrm{M}(\mathrm{mm})$ & $\mathrm{V}\left(\mathrm{mm}^{2}\right)$ \\
\hline 1 & $\Delta x_{x}$ & normal distribution & 0.0040 & $0.05 / 6$ \\
\hline 2 & $\Delta y_{x}$ & normal distribution & 0.0039 & $0.05 / 6$ \\
\hline 3 & $\Delta z_{x}$ & normal distribution & 0.0038 & $0.05 / 6$ \\
\hline 4 & $\Delta a_{x}$ & normal distribution & $0.0025 / 1000$ & $0.03 / 6000$ \\
\hline 5 & $\Delta \beta_{x}$ & normal distribution & $0.0027 / 1000$ & $0.06 / 6000$ \\
\hline 6 & $\Delta y_{x}$ & normal distribution & $0.00242 / 1000$ & $0.05 / 6000$ \\
\hline 7 & $\Delta x_{y}$ & normal distribution & 0.0038 & $0.04 / 6$ \\
\hline 8 & $\Delta y_{y}$ & normal distribution & 0.0040 & $0.05 / 6$ \\
\hline 9 & $\Delta z_{y}$ & normal distribution & 0.0044 & $0.04 / 6$ \\
\hline 10 & $\Delta a_{y}$ & normal distribution & $0.00253 / 1000$ & $0.05 / 6000$ \\
\hline 11 & $\Delta \beta_{y}$ & normal distribution & $0.00242 / 1000$ & $0.04 / 6000$ \\
\hline 12 & $\Delta \gamma_{y}$ & normal distribution & $0.00224 / 1000$ & $0.04 / 6000$ \\
\hline 13 & $\Delta x_{z}$ & normal distribution & 0.0035 & $0.03 / 6$ \\
\hline 14 & $\Delta y_{z}$ & normal distribution & 0.0041 & $0.03 / 6$ \\
\hline 15 & $\Delta z_{z}$ & normal distribution & 0.0043 & $0.05 / 6$ \\
\hline 16 & $\Delta a_{z}$ & normal distribution & $0.00233 / 1000$ & $0.03 / 6000$ \\
\hline 17 & $\Delta \beta_{z}$ & normal distribution & $0.00259 / 1000$ & $0.04 / 6000$ \\
\hline 18 & $\Delta \gamma_{z}$ & normal distribution & $0.00252 / 1000$ & $0.03 / 6000$ \\
\hline 19 & $\Delta x_{A}$ & normal distribution & 0.0058 & $0.017 / 6$ \\
\hline 20 & $\Delta y_{A}$ & normal distribution & 0.0062 & $0.021 / 6$ \\
\hline 21 & $\Delta z_{A}$ & normal distribution & 0.0065 & $0.024 / 6$ \\
\hline 22 & $\Delta a_{A}$ & normal distribution & $0.00583 / 1000$ & $0.02 / 6000$ \\
\hline 23 & $\Delta \beta_{A}$ & normal distribution & $0.03219 / 1000$ & $0.02 / 6000$ \\
\hline 24 & $\Delta \gamma_{A}$ & normal distribution & $0.00692 / 1000$ & $0.04 / 6000$ \\
\hline
\end{tabular}

Table 8. Failure probabilities of the different failure modes at $x=200 \mathrm{~mm}$, $y=400 \mathrm{~mm}, z=300 \mathrm{~mm}$

\begin{tabular}{cccccccc}
\hline \hline Failure mode & $M_{1}$ & $M_{2}$ & $M_{3}$ & $M_{4}$ & $M_{5}$ & $M_{6}$ & $M_{7}$ \\
\hline Failure probability (\%) & 0.09 & 0.81 & 0.55 & 0.111 & 0.77 & 0.29 & 0.35 \\
\hline \hline
\end{tabular}

Table 9. Results of the machining accuracy reliability sensitivity analysis at $x=200 \mathrm{~mm}, y=400 \mathrm{~mm}, z=300 \mathrm{~mm}$

\begin{tabular}{|c|c|c|c|c|c|c|c|}
\hline \multirow{2}{*}{$\begin{array}{l}\text { Geo- } \\
\text { metric } \\
\text { errors }\end{array}$} & \multicolumn{7}{|c|}{ Sensitivity coefficient } \\
\hline & $M_{1}$ & $M_{2}$ & $M_{3}$ & $M_{4}$ & $M_{5}$ & $M_{6}$ & $M_{7}$ \\
\hline$\Delta x_{x}$ & 0.0304 & 0.0154 & 0.0681 & 0.0318 & 0.0493 & 0.0251 & 0.0789 \\
\hline$\Delta y_{x}$ & 0.0352 & 0.0858 & 0.0591 & 0.0432 & 0.0434 & 0.0842 & 0.0321 \\
\hline$\Delta z_{x}$ & 0.0010 & 0.0540 & 0.0135 & 0.0503 & 0.0430 & 0.0098 & 0.0278 \\
\hline$\Delta a_{x}$ & 0.0572 & 0.0618 & 0.0697 & 0.0252 & 0.0334 & 0.0093 & 0.0205 \\
\hline$\Delta \beta_{x}$ & 0.0571 & 0.0390 & 0.0485 & 0.0005 & 0.0275 & 0.0742 & 0.0556 \\
\hline$\Delta \gamma_{x}$ & 0.0120 & 0.0516 & 0.0682 & 0.0817 & 0.0725 & 0.0539 & 0.0775 \\
\hline$\Delta x_{y}$ & 0.0122 & 0.0591 & 0.0348 & 0.0720 & 0.0364 & 0.0303 & 0.0458 \\
\hline$\Delta y_{y}$ & 0.0674 & 0.0405 & 0.0453 & 0.0369 & 0.0015 & 0.0270 & 0.0756 \\
\hline$\Delta z_{y}$ & 0.0488 & 0.0271 & 0.0632 & 0.0573 & 0.0419 & 0.0768 & 0.0396 \\
\hline$\Delta a_{y}$ & 0.0341 & 0.0109 & 0.0649 & 0.0009 & 0.0058 & 0.0863 & 0.0458 \\
\hline$\Delta \beta_{y}$ & 0.0518 & 0.0369 & 0.0626 & 0.0117 & 0.0249 & 0.0176 & 0.0004 \\
\hline$\Delta \gamma_{y}$ & $0.011 \mathrm{~h} 8$ & 0.0295 & 0.0085 & 0.0276 & 0.0387 & 0.0161 & 0.0170 \\
\hline$\Delta x_{z}$ & 0.0824 & 0.0133 & 0.0342 & 0.0860 & 0.0699 & 0.0638 & 0.0021 \\
\hline$\Delta y_{z}$ & 0.0798 & 0.0454 & 0.0155 & 0.0066 & 0.0677 & 0.0501 & 0.0689 \\
\hline$\Delta z_{z}$ & 0.0447 & 0.0406 & 0.0061 & 0.0586 & 0.0745 & 0.0871 & 0.0476 \\
\hline$\Delta a_{z}$ & 0.0504 & 0.0496 & 0.0384 & 0.0443 & 0.0795 & 0.0078 & 0.0793 \\
\hline$\Delta \beta_{z}$ & 0.0205 & 0.0367 & 0.0659 & 389 & 0.0091 & 14 & 0.0398 \\
\hline$\Delta \gamma_{z}$ & 0.0864 & 0.0026 & 0.0361 & 0.0685 & 0.0613 & 0.0322 & 0.0433 \\
\hline$\Delta x_{A}$ & 0.0577 & 0.0382 & 0.0707 & 0.0741 & 0.0098 & 0.0552 & 0.0582 \\
\hline$\Delta y_{A}$ & 0.0271 & 0.0197 & 0.0064 & 0.0399 & 0.0494 & 0.0086 & 0.0302 \\
\hline$\Delta z_{A}$ & 0.0152 & 0.0581 & 0.0547 & 0.0362 & 0.0241 & 0.0224 & 0.0131 \\
\hline$\Delta a_{A}$ & 0.0329 & 0.0496 & 0.0095 & 0.0415 & 0.0559 & 0.0597 & 0.0750 \\
\hline$\Delta \beta_{A}$ & 0.0017 & 0.0771 & 0.0434 & 0.0577 & 0.0097 & 0.0829 & 0.0046 \\
\hline$\Delta \gamma_{A}$ & 0.0821 & 0.0572 & 0.0128 & 0.0086 & 0.0707 & 0.0182 & 0.0213 \\
\hline \multicolumn{8}{|c|}{$\hat{S}_{\mu_{k}}^{(i)}=\frac{1}{33} \sum_{j=1}^{33}{ }^{j} S_{\mu_{k}}^{(i)}$} \\
\hline & & & $\hat{S}_{\sigma_{k}}^{(i)}=$ & $-\sum_{j=1}^{33} j_{S}$ & & & (63) \\
\hline
\end{tabular}

The results obtained for the failure probabilities of the different failure modes and the machining accuracy reliability sensitivities of defined as ${ }^{j} S_{\mu_{k}}^{(i)}$, and the machining accuracy reliability sensitivity of the variance $\sigma_{k}$ of geometric error $g_{k}$ at the test point “j”, was defined as ${ }^{j} S_{\sigma_{k}}^{(i)}$. Then, for the whole working space, the machining accuracy reliability sensitivity of the mean value $\mu_{k}$ and the variance $\sigma_{k}$ of geometric error $g_{k}$ for the $i^{\text {th }}$ failure mode $M_{i}$, can be defined as $\hat{S}_{\mu_{k}}^{(i)}$ and $\hat{S}_{\sigma_{k}}^{(i)}$, respectively.

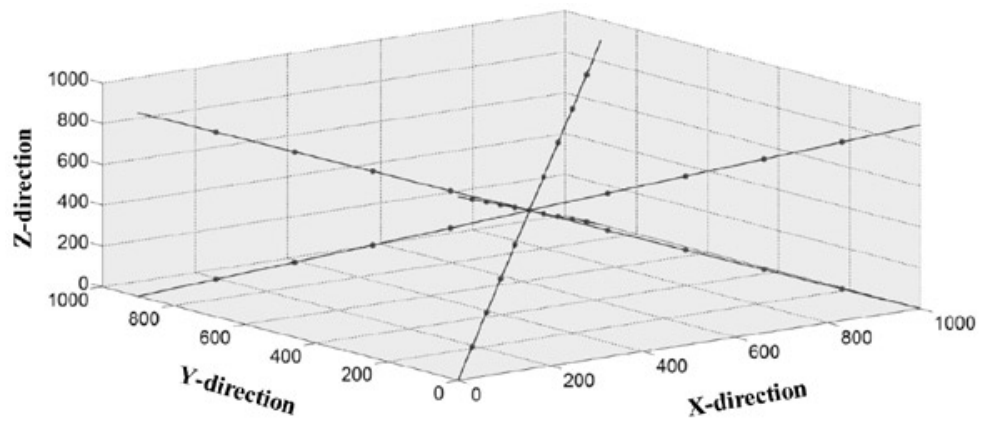

Fig. 4. Distribution of the test points. 
Table 10. Failure probabilities of the different failure modes for the whole working space

\begin{tabular}{cccccccc}
\hline \hline Failure mode & $M_{1}$ & $M_{2}$ & $M_{3}$ & $M_{4}$ & $M_{5}$ & $M_{6}$ & $M_{7}$ \\
\hline Failure probability(\%) & 0.06 & 0.71 & 1.06 & 0.46 & 0.43 & 0.95 & 0.40 \\
\hline \hline
\end{tabular}

Table 11. Results of the machining accuracy reliability sensitivity analysis for the whole working space

\begin{tabular}{|c|c|c|c|c|c|c|c||}
\hline \multirow{2}{*}{$\begin{array}{c}\text { Geo- } \\
\text { metric } \\
\text { errors }\end{array}$} & \multicolumn{7}{|c||}{ Sensitivity coefficient } \\
\cline { 2 - 8 } & $M_{1}$ & $M_{2}$ & $M_{3}$ & $M_{4}$ & $M_{5}$ & $M_{6}$ & $M_{7}$ \\
\hline$\Delta x_{x}$ & 0.0774 & 0.0358 & 0.0099 & 0.0318 & 0.0637 & 0.0305 & 0.0046 \\
\hline$\Delta y_{x}$ & 0.0082 & 0.0613 & 0.0089 & 0.0560 & 0.0160 & 0.0196 & 0.0296 \\
\hline$\Delta z_{x}$ & 0.0398 & 0.0236 & 0.0623 & 0.0577 & 0.0366 & 0.0691 & 0.0587 \\
\hline$\Delta a_{x}$ & 0.0817 & 0.0032 & 0.0349 & 0.0442 & 0.0343 & 0.0164 & 0.0423 \\
\hline$\Delta \beta_{x}$ & 0.0134 & 0.0342 & 0.0173 & 0.0069 & 0.0572 & 0.0402 & 0.0441 \\
\hline$\Delta y_{x}$ & 0.0381 & 0.0435 & 0.0083 & 0.0813 & 0.0226 & 0.0302 & 0.0883 \\
\hline$\Delta x_{y}$ & 0.0435 & 0.0083 & 0.0418 & 0.0306 & 0.0535 & 0.0412 & 0.0506 \\
\hline$\Delta y_{y}$ & 0.0247 & 0.0502 & 0.0119 & 0.0056 & 0.0713 & 0.0574 & 0.0436 \\
\hline$\Delta z_{y}$ & 0.0380 & 0.0364 & 0.0543 & 0.0509 & 0.0702 & 0.0226 & 0.0472 \\
\hline$\Delta a_{y}$ & 0.0083 & 0.0483 & 0.0604 & 0.0249 & 0.0007 & 0.0174 & 0.0838 \\
\hline$\Delta \beta_{y}$ & 0.0623 & 0.0684 & 0.0413 & 0.0554 & 0.0429 & 0.0247 & 0.0059 \\
\hline$\Delta \gamma_{y}$ & 0.0539 & 0.0413 & 0.0414 & 0.0456 & 0.0599 & 0.0207 & 0.0822 \\
\hline$\Delta x_{z}$ & 0.0743 & 0.0690 & 0.0702 & 0.0362 & 0.0659 & 0.0071 & 0.0226 \\
\hline$\Delta y_{z}$ & 0.0289 & 0.0204 & 0.0737 & 0.0264 & 0.0273 & 0.0693 & 0.0147 \\
\hline$\Delta z_{z}$ & 0.0074 & 0.0237 & 0.0462 & 0.0603 & 0.0693 & 0.0555 & 0.0677 \\
\hline$\Delta a_{z}$ & 0.0186 & 0.0167 & 0.0570 & 0.0175 & 0.0393 & 0.0416 & 0.0156 \\
\hline$\Delta \beta_{z}$ & 0.0296 & 0.0193 & 0.0318 & 0.0462 & 0.0190 & 0.0403 & 0.0624 \\
\hline$\Delta \gamma_{z}$ & 0.0724 & 0.0284 & 0.0785 & 0.0499 & 0.0676 & 0.0616 & 0.0835 \\
\hline$\Delta x_{A}$ & 0.0761 & 0.0261 & 0.0073 & 0.0606 & 0.0014 & 0.0682 & 0.0008 \\
\hline$\Delta y_{A}$ & 0.0411 & 0.0395 & 0.0448 & 0.0297 & 0.0114 & 0.0439 & 0.0457 \\
\hline$\Delta z_{A}$ & 0.0176 & 0.0687 & 0.0319 & 0.0821 & 0.0779 & 0.0284 & 0.0102 \\
\hline$\Delta a_{A}$ & 0.0679 & 0.0871 & 0.0788 & 0.0651 & 0.0187 & 0.0680 & 0.0296 \\
\hline$\Delta \beta_{A}$ & 0.0350 & 0.0679 & 0.0549 & 0.0228 & 0.0087 & 0.0626 & 0.0396 \\
\hline$\Delta \gamma_{A}$ & 0.0419 & 0.0786 & 0.0322 & 0.0122 & 0.0646 & 0.0637 & 0.0267 \\
\hline & & & & & & & \\
\hline
\end{tabular}

the whole working space are listed in Table 10 and Table 11, respectively.

In order to study the machining accuracy reliability of the selected machining center in a real processing environment, the machining center has been used to machine a specific part. A photograph of the machining site is shown in Fig.5. The main parameters for the machining process are listed in Table 12.

In a modern advanced machining line, in order to improve the efficiency and production rhythm of the whole automatic production line, one machine only needs to complete one or just a few machining steps. For the selected machine, in a production line, it only needs to machine the machining surface of the reduction gearbox which has been marked in Fig.5. The machining quality of the machining surface is affected by the machining accuracy reliability of the machine center in the Z-
Table 12. Main parameters of the machining process.

\begin{tabular}{|c|c|c|c|c|c|c|}
\hline No & Tool & Illustration & $\begin{array}{l}\text { Axial cutting } \\
\text { depth }(\mathrm{mm})\end{array}$ & $\begin{array}{l}\text { Radial cutting } \\
\text { depth }(\mathrm{mm})\end{array}$ & $\begin{array}{l}\text { Spindle speed } \\
(\mathrm{r} / \mathrm{min})\end{array}$ & $\begin{array}{c}\text { Feed speed } \\
(\mathrm{mm} / \mathrm{min})\end{array}$ \\
\hline 1 & $\begin{array}{l}\text { Milling cutter } \\
\text { F4AS2000ADL38 }\end{array}$ & $\begin{array}{l}\text { Rough ma- } \\
\text { chining }\end{array}$ & 2 & 10 & 12000 & 4000 \\
\hline 2 & $\begin{array}{l}\text { Boring tool } \\
\text { SS2OFBHS24 }\end{array}$ & $\begin{array}{l}\text { Precision bor- } \\
\text { ing machining }\end{array}$ & 2 & 0.2 & 12000 & 2000 \\
\hline 3 & $\begin{array}{l}\text { Face milling cutter } \\
\text { D125 }\end{array}$ & $\begin{array}{l}\text { Finish-milling } \\
\text { top surface }\end{array}$ & 0.2 & 10 & 3000 & 3000 \\
\hline
\end{tabular}

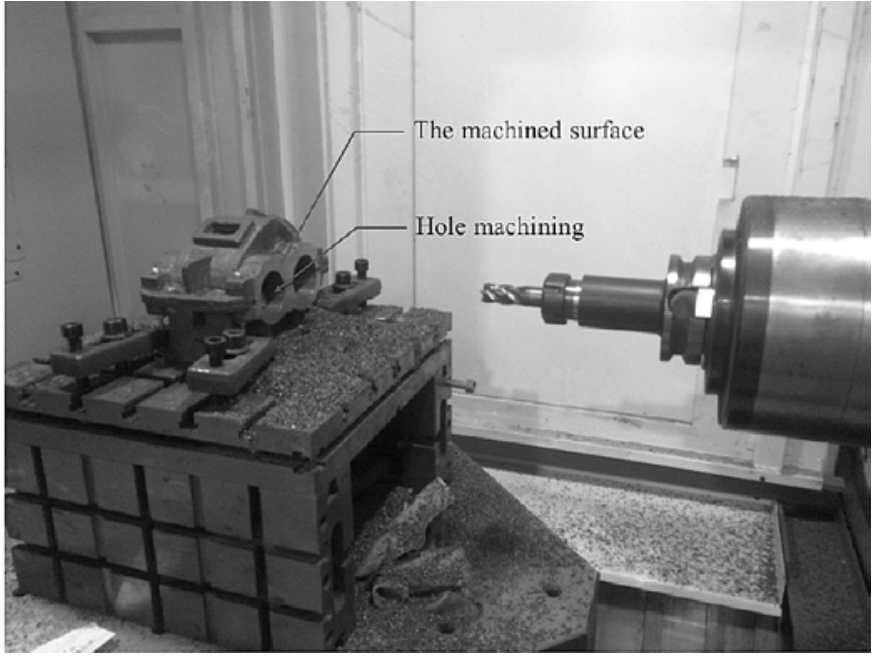

Fig.5 Photograph of the machining site.

direction. As shown in Eqs.(10) to (16), only $M_{3}, M_{5}, M_{6}$ and $M_{7}$ are related to the machining accuracy reliability of the machine center in Z-direction. As shown in Table 9, the failure probabilities of $M_{3}$ and $M_{6}$ are greater than the failure probabilities of $M_{5}$ and $M_{7}$. So $M_{3}$ and $M_{6}$ are the critical failure modes which significantly affect the machining quality of the machining surface.

As shown in Table 8, for failure mode $M_{3}$, the sensitivity coefficients obtained for and were highest. For the failure mode $M_{6}$, the sensitivity coefficient of and were the highest. Thus,, , and can be identified as the most crucial errors that affect $M_{3}$ and $M_{6}$.

Because the geometric errors of the machine tool are linked to the geometric accuracy of the feeding components, there exist mapping relationships between the basic geometric errors and the accuracy parameters of the feeding components. The corresponding relationships between the basic geometric errors and the accuracy parameters of the components [2] are illustrated in Table 13.

Consequentially, the following modifications can be adopted to improve the machining accuracy: (1) Improving the straightness in the vertical plane of the X-guideway; (2) Improving the straightness in the horizontal plane of the Z-guideway; (3) Improving the parallelism of the Z-guideway; (4) Switching to a higher precision screw for the A-axis.

The failure probabilities of the different failure modes for the whole working space after modification were analyzed and are listed in Table 14. The comparison revealed that the failure probabilities were reduced after modification, and the failure probabilities of the failure modes and were greatly reduced after modification. Thus, we can conclude that the proposed machining accuracy reliability sensitivity analysis method is both feasible and effective. 
Table 13. Corresponding relationships between the basic geometric errors and the accuracy parameters of the components

\begin{tabular}{cl}
\hline \hline Basic geometric errors & Accuracy parameters of the components \\
\hline$\Delta x_{x}, \Delta y_{y}$ and $\Delta z_{z}$ & Cumulative pitch error of the lead screw \\
$\Delta z_{x}, \Delta z_{y}$ and $\Delta x_{z}$ & Straightness error in the vertical plane of the guideway \\
$\Delta y_{x}, \Delta x_{y}$ and $\Delta y_{z}$ & Straightness error in the horizontal plane of the guideway \\
$\Delta a_{x}, \Delta \beta_{y}$ and $\Delta y_{z}$ & Parallelism error of the guideway \\
$\Delta \beta_{x}, \Delta a_{y}$ and $\Delta \beta_{z}$ & Straightness error in the vertical plane of the guideway and length of the moving parts \\
$\Delta y_{x}, \Delta y_{y}$ and $\Delta a_{z}$ & Straightness error in the horizontal plane of the guideway and length of the moving parts \\
$\Delta x_{A}$ & Center distance deviation of the worm gear pairs \\
$\Delta y_{A}$ & Center plane error of the worm gear pair \\
$\Delta z_{A}$ & Radial pulsation of the turbine gear ring \\
$\Delta a_{A}$ & Cumulative pitch error of the gear pairs and length of the moving parts \\
$\Delta \beta_{A}$ & Gear ring radial pulsation of the worm wheel and length of the moving parts \\
$\Delta y_{A}$ & Center distance deviation of the worm gear pairs and length of the moving parts
\end{tabular}

Table 14. Failure probabilities of the different failure mode for the whole working space after modification.

\begin{tabular}{lccccccc}
\hline \hline Failure mode & $M_{1}$ & $M_{2}$ & $M_{3}$ & $M_{4}$ & $M_{5}$ & $M_{6}$ & $M_{7}$ \\
\hline Failure probability (\%) & 0.058 & 0.70 & 0.60 & 0.46 & 0.40 & 0.61 & 0.36 \\
\hline
\end{tabular}

\section{Conclusions}

In precision manufacturing, the geometric errors of a machine tool considerably affect the machining accuracy reliability of the machine tool, which directly determines the geometrical and dimensional accuracy of the machined product. Therefore, establishing the relationship between the geometric errors and the machining accuracy reliability and then efficiently improving the machining accuracy reliability are the key steps required to improve the achievable product quality.

In this paper, a new approach for analyzing the sensitivity of the machining accuracy reliability of machine tools based on fast Markov chain simulations was proposed. This method has the following two characteristics:

(1) The proposed analytical method can be used to establish the relationship between the model of the stochastic geometric errors and the machining accuracy reliability and to identify the key geometric errors that have the biggest impact on the machining accuracy reliability. According to the analysis results, the crucial geometric errors can be purposefully modified and the machining accuracy reliability can be dramatically improved. In addition, the results of the sensitivity analysis can also offer a good reference for an optimal design, accuracy control and error compensation of a complex machine.

(2) Employing the proposed analytical method, we identified seven failure modes of the machine tool. In a modern advanced machining line, in order to improve the efficiency and production rhythm of the whole automatic production line, one machine only needs to complete one or just a few machining steps. Considering the actual needs, the failure modes of the machine tools which need to be improved can be isolated, thereby greatly reducing the maintenance costs of machine tools.

Despite the progress, it should be pointed out that the geometric errors analyzed in this paper are quasi-static and correspond to coldstart conditions. The dynamic fluctuations caused by axis acceleration, dynamic load-induced errors and thermal errors were not taken into consideration. Therefore, the geometric errors under working conditions, which of course are of great practical significance, need to be further studied.

\section{Acknowledgement}

This work was financially supported by the National Natural Science Foundation of China (Grant No. 51575010, 51575009), the Beijing Nova Program (Grant No. Z1511000003150138), the Leading Talent Project of Guangdong Province, the Open Research Fund of the Key Laboratory of High Performance Complex Manufacturing, Central South University (Grant No. Kfkt2014-09), and the Shantou Light Industry Equipment Research Institute of Science and Technology Correspondent Station (Grant No. 2013B090900008).

\section{References}

1. Avontuur GC, van der Werff K. Systems reliability analysis of mechanical and hydraulic drive systems. Reliability Engineering \& System Safety 2002; 77(2):121-130, http://dx.doi.org/10.1016/S0951-8320(02)00039-X.

2. Bohez EL, Ariyajunya B, Sinlapeecheewa C, et al. Systematic geometric rigid body error identification of 5-axis milling machines. Computeraided design 2007b; 39(4): 229-244.

3. Cai L, Zhang Z, Cheng Q, Liu Z, Gu P. A geometric accuracy design method of multi-axis NC machine tool for improving machining accuracy reliability. Eksploatacja i Niezawodnosc - Maintenance and Reliability 2015; 17(1): 143-155, http://dx.doi.org/10.17531/ein.2015.1.19.

4. Çaydaş U, Ekici S. Support vector machines models for surface roughness prediction in CNC turning of AISI 304 austenitic stainless steel. Journal of Intelligent Manufacturing 2012; 23(3): 639-650, http://dx.doi.org/10.1007/s10845-010-0415-2.

5. Chen B, Chen X, Li B, et al. Reliability estimation for cutting tools based on logistic regression model using vibration signals. Mechanical Systems and Signal Processing 2011; 25(7): 2526-2537, http://dx.doi.org/10.1016/j.ymssp.2011.03.001.

6. Chen G, Liang Y, Sun Y, et al. Volumetric error modeling and sensitivity analysis for designing a five-axis ultra-precision machine tool. The International Journal of Advanced Manufacturing Technology 2013; 68(9-12): 2525-2534, http://dx.doi.org/10.1007/s00170-013-4874-4.

7. Cheng Q, Zhao H, Zhang G, et al. An analytical approach for crucial geometric errors identification of multi-axis machine tool based on global sensitivity analysis. The International Journal of Advanced Manufacturing Technology 2014, 75(1-4): 107-121, http://dx.doi. org/10.1007/s00170-014-6133-8.

8. De-Lataliade A, Blanco S, Clergent Y. Monte Carlo method and sensitivity estimations. Journal of Quantitative Spectroscopy and Radiative Transfer 2007; 75(5): 529-538, http://dx.doi.org/10.1016/S0022-4073(02)00027-4.

9. Du X, Sudjianto A, Huang B. Reliability-Based Design With the Mixture of Random and Interval Variables. Journal of Mechanical Design 2005; 127(6): 1068-1076, http://dx.doi.org/10.1115/1.1992510. 
10. Eman KF, Wu BT, DeVries MF. A Generalized Geometric Error Model for Multi-Axis Machines. Annals of the CIRP 1987; 36(07): 253-256, http://dx.doi.org/10.1016/S0007-8506(07)62598-0.

11. Fu G, Fu J, Xu Y, et al. Product of exponential model for geometric error integration of multi-axis machine tools. The International Journal of Advanced Manufacturing Technology 2014; 71(9-12): 1653-1667, http://dx.doi.org/10.1007/s00170-013-5586-5.

12. Ghosh R, Chakraborty S, Bhattacharyya B. Stochastic Sensitivity Analysis of Structures Using First-order Perturbation. Meccanica 2001; 36(3): 291-296, http://dx.doi.org/10.1023/A:1013951114519.

13. Guo J, Du X. Reliability sensitivity analysis with random and interval variables. International Journal for Numerical Methods in Engineering 2009; 78(13): 1585-1617, http://dx.doi.org/10.1002/nme.2543.

14. Habibi M, Arezoo B, Nojedeh MV. Tool deflection and geometrical error compensation by tool path modification. International Journal of Machine Tools and Manufacture 2011; 51(6): 439-449, http://dx.doi.org/10.1016/j.ijmachtools.2011.01.009.

15. Homma T, Saltelli A. Importance measures in global sensitivity analysis of nonlinear models. Reliability Engineering \& System Safety 1996; 52(1): 1-17, http://dx.doi.org/10.1016/0951-8320(96)00002-6.

16. Jha BK, Kumar A. Analysis of geometric errors associated with five-axis machining center in improving the quality of cam profile. International Journal of Machine Tools and Manufacture 2003; 43(6): 629-636, http://dx.doi.org/10.1016/S0890-6955(02)00268-7.

17. Kim K, Kim MK. Volumetric accuracy analysis based on generalized geometric error model in multi-axis machine tools. Mechanism and Machine Theory 1991; 26(2): 207-219, http://dx.doi.org/10.1016/0094-114X(91)90084-H.

18. Lei WT, Hsu YY. Accuracy enhancement of five-axis CNC machines through real-time error compensation. International Journal of Machine Tools and Manufacture 2003; 43(9): 871-877. http://dx.doi.org/10.1016/S0890-6955(03)00089-0.

19. Lin PD, Tzeng CS. Modeling and measurement of active parameters and workpiece home position of a multi-axis machine tool. International Journal of Machine Tools and Manufacture 2008; 48(3-4): 338-349, http://dx.doi.org/10.1016/j.ijmachtools.2007.10.004.

20. Liu H, Li B, Wang X, Tan G. Characteristics of and measurement methods for geometric errors in CNC machine tools. The International Journal of Advanced Manufacturing Technology 2011; 54(1-4): 195-201, http://dx.doi.org/10.1007/s00170-010-2924-8.

21. Liu YW. Applications of multi-body dynamics in the field of mechanical engineering. Chinese Journal of Mechanical Engineering 2000; 11(1): 144-149.

22. Lin TR. Reliability and failure of face-milling tools when cutting stainless steel. Journal of Materials Processing Technology 1998; 79(1): 41-46, http://dx.doi.org/10.1016/S0924-0136(97)00451-2.

23. Shin YC, Chin H, Brink MJ. Characterization of CNC machining centers. Journal of Manufacturing Systems 1991; 10(5): 407-421, http:// dx.doi.org/10.1016/0278-6125(91)90058-A.

24. Stryczek R. A metaheuristic for fast machining error compensation. Journal of Intelligent Manufacturing 2014; 1-12, http://dx.doi.org/10.1007/ s10845-014-0945-0.

25. Soons JA, Theuws FC, Schellekens PH. Modeling the errors of multi-axis machines: a general methodology. Precision Engineering 1992; 14(1): 5-19, http://dx.doi.org/10.1016/0141-6359(92)90137-L.

26. Tang J. Mechanical system reliability analysis using a combination of graph theory and Boolean function. Reliability Engineering \& System Safety 2001; 72(1): 21-30, http://dx.doi.org/10.1016/S0951-8320(00)00099-5.

27. Tsutsumi M, Saito A. Identification of angular and positional deviations inherent to 5-axis machining centers with a tilting-rotary table by simultaneous four-axis control movements. International Journal of Machine Tools and Manufacture 2004; 44(12-13): 1333-1342, http:// dx.doi.org/10.1016/j.ijmachtools.2004.04.013.

28. Xiao NC, Huang HZ, Wang Z, et al. Reliability sensitivity analysis for structural systems in interval probability form. Structural and Multidisciplinary Optimization 2011; 44(5): 691-705, http://dx.doi.org/10.1007/s00158-011-0652-9.

29. Xu C, Gertner G. Extending a global sensitivity analysis technique to models with correlated parameters. Computational Statistics \& Data Analysis 2007; 51(12): 5579-5590, http://dx.doi.org/10.1016/j.csda.2007.04.003.

30. Yan S, Li B, Hong J. Bionic design and verification of high-precision machine tool structures. The International Journal of Advanced Manufacturing Technology 2015; 1-13, http://dx.doi.org/10.1007/s00170-015-7155-6.

31. Zhang Y M, Wen BC, Liu QL. Reliability sensitivity for rotor-stator systems with rubbing. Journal of Sound and Vibration 2003; 259(5): 1095-1107, http://dx.doi.org/10.1006/jsvi.2002.5117.

32. Zhu S, Ding G, Qin S, et al. Integrated geometric error modeling, identification and compensation of CNC machine tools. International Journal of Machine Tools and Manufacture 2012; 52(1): 24-29, http://dx.doi.org/10.1016/j.ijmachtools.2011.08.011.

\section{Qiang CHENG \\ Bingwei SUN \\ Yongsheng ZHAO}

Beijing Key Laboratory of Advanced Manufacturing Technology, Beijing University of Technology, Beijing 100124, China

\section{Peihua GU}

Department of Mechatronics Engineering, Shantou University, Shantou, Guangdong, 515063, China

Emails: chengqiang@bjut.edu.cn,1359750743@qq.com,yszhao@bjut.edu.cn, gupeihua@aliyun.com 